\title{
$\underline{\operatorname{articles}}$
}

\section{Lifestyle Entrepreneurship and Innovation in Rural Areas: The Case of Tourism Entrepreneurs}

\author{
Álvaro Dias ${ }^{1} \oplus^{a}$, Graça Miranda Silva ${ }^{2} \oplus^{b}$ \\ 1 Universidade Lusófona/TRIE; ISCTE-IUL, ${ }^{2}$ ADVANCE/CSG, ISEG, Lisbon School of Economics \& Management, Universidade de Lisboa \\ Keywords: Lifestyle entrepreneurship, Rural Tourism, Innovation, Place attachment, Local Knowledge \\ https://doi.org/10.53703/001c.29474
}

\section{Journal of Small Business Strategy}

Vol. 31, Issue 4, 2021

\begin{abstract}
Lifestyle entrepreneurs play an important role in innovation and sustainability in rural destinations. Their competitiveness depends largely on how they explore their link to the place and generate innovation. To analyze the relationship between the link to the place and innovation, this article uses survey data from a sample of 221 rural lifestyle entrepreneurs. Using PLS-SEM modeling, the results indicate that place familiarity and relational capital positively influence innovation. Furthermore, place familiarity reveals as an important factor for improving relational capital. In its turn, the degree of relational capital contributes positively to the small firm's knowledge absorption. The results also reveal that, although there is no direct relation between knowledge absorption and innovation, relational capital mediates the relationship between place familiarity and innovation and that there is an indirect relationship between relational capital and innovation, through the mediating effect of knowledge absorption. These results provides important elements for rural tourism destination decision making on innovation and competitiveness.
\end{abstract}

\section{Introduction}

In the universe of small businesses, lifestyle entrepreneurs (LE) represent a significant portion (Getz \& Carlsen, 2000; Thomas et al., 2011), being associated with innovative and more sustainable practices when compared to large companies (Bosworth \& Farrell, 2011; Stamboulis \& Skayannis, 2003; Wang et al., 2019). Nevertheless, research on this class of entrepreneurs is still scarce (Dias et al., 2020a; Hoarau, 2014).

They represent a specific class of entrepreneurs, distin- guished from others by the fact that they combine (or even substitute) financial objectives with other non-financial indicators, such as lifestyle, independence, social or environmental (Thomas et al., 2011). This particularity reveals that traditional models of entrepreneurship must be reviewed to identify the specificities of these entrepreneurs. One of their essential characteristics is their strong link to the place (Carlsen et al., 2008; Kibler et al., 2015), which provides them with a source of differentiation where they support their competitiveness compared to large companies (Komppula, 2014). In rural context, the interplay between

\footnotetext{
a Universidade Lusófona/TRIE, ECEO, Campo Grande, 376, 1749-024 Lisbon, Portugal, and ISCTE-IUL, Lisbon, Portugal; alvaro.dias1@gmail.com
}

Álvaro Lopes Dias is a Professor of Strategy and Entrepreneurship at Universidade Lusófona and ISCTE-IUL, both in Lisbon, Portugal. Ph.D. in Management, Ph.D. in Tourism, and MBA in International Business. Professor Dias has over 26 years of teaching experience. He has had several visiting positions in different countries and institutions including Brazil, Angola, Spain, Poland, and Finland. He regularly teaches in English, Portuguese, and Spanish at undergraduate, master and doctorate levels, as well as in executive programs. Professor Dias has produced extensive research in the field of Tourism and Management, including books, book chapters, papers in scientific journals and conference proceedings, case studies, and working papers.

b ADVANCE/CSG, ISEG, Lisbon School of Economics \& Management, Universidade de Lisboa, Rua Miguel Lupi n²0, $1249-078$ Lisbon, Portugal; gracamsilva@iseg.ulisboa.pt

Graça Miranda Silva is an Assistant Professor in the Lisbon School of Economics \& Management (ISEG) at Universidade de Lisboa. She earned her PhD in Industrial Engineering, majoring in quality management, from Faculdade de Ciências e Tecnologia (FCTUNL). Her research primarily focuses on Quality Management (e.g., TQM), Innovation Management (e.g., radical and incremental Innovation, product and process innovation), and Sustainability (e.g., green supply chain management, social and environmental practices). Her research has appeared in International Journal of Operations \& Production Management, Business Strategy and the Environment, Industrial Marketing Management, Journal of Business Research, and Journal of International Marketing among others.

Graça Miranda Silva acknowledges the support of national funds through FCT - Fundação para a Ciência e a Tecnologia, I.P., Project UIDB/04521/2020. 
the entrepreneur, the regional setting, and the place - specific qualities, constitutes a key driver for change and innovation (Korsgaard et al., 2015; Xiong et al., 2020). However, this link to the place where they develop their activity still remains little explored (Kibler et al., 2015), especially in the relation and contribution to innovation (Hjalager et al., 2018). Research on LE has focused on the characteristics of entrepreneurs, and it is clear that entrepreneurial processes are still under-explored (Fu et al., 2019). In particular, it is necessary to extend the existing knowledge regarding the transformation of this link to the place into innovation and to understand the basis of the competitiveness of these entrepreneurs ((Dias et al., 2020a; García-Rosell et al., 2019). This knowledge is very useful to create local development strategies, to create jobs and attract investment and tourists and visitors to rural areas, avoiding imitating tourist attractions that cause the homogenization of the value propositions of the rural destinations.

Thus, this study has as objectives (i) to perceive the implications of the link to the place and the relational capital in the innovation generated by LE in rural areas; (ii) to identify the role of knowledge absorption in the innovation generated by LE. To achieve these objectives, this study focuses on a specific sector where there is a strong predominance of these entrepreneurs - tourism in rural areas.

The article is structured as follows. The following section presents the theoretical framework. Section three details the methodology. Section four presents the results and the discussion. Finally the conclusions, limitations and future research guidelines are outlined.

\section{Theoretical framework}

\subsection{Place familiarity and local knowledge}

For this research sake, place familiarity can be defined as the perception of how much an entrepreneur knows about a destination (Tan \& Chang, 2016). Tourist experiences can benefit in authenticity and degree of immersion in local culture by combining the practice and distinctive features of the place (Anderson, 2012), in its idiosyncrasy of natural and cultural attractions and of narratives, stories, and legends (Bosworth \& Farrell, 2011) and customs (Valtonen, 2009), with a strong personal imprint (Hoarau, 2014).

The uniqueness of the place thus holds a potential for differentiation and value creation in tourist experiences (Cooper, 2015), the basis of LE competitiveness compared to large companies (Komppula, 2014). However, this requires a step ahead, i.e. that entrepreneurs should be able to access and appropriate this knowledge and transform it into new narratives and meaningful destination-specific experiences (Stamboulis \& Skayannis, 2003). The problem is that local knowledge is tacit (Hoarau, 2014) and practice based (Arias \& Cruz, 2019), requiring an ability to interpret symbolic and non-verbal information dispersed across a multiplicity of sources (Hall, 2019).

By being embedded in the local community there is a unique opportunity to access this local knowledge (Bredvold \& Skålén, 2016). The mere fact that they are integrated into the local social structure (Bredvold \& Skålén, 2016; Jack \& Anderson, 2002) and live in a specific location (Valtonen, 2009) facilitates socialization processes (Zhang et al., 2015). In addition, participation in the local community not only facilitates involvement in social practices but also tracks the continuous evolution of local knowledge (GarcíaRosell et al., 2019) through observation, listening and development of joint activities (Valtonen, 2009).

At the same time, by being embedded in the local community, LE have the opportunity to involve and stimulate the collaboration of local stakeholders, resulting, on the one hand, in access to more and better knowledge (Czernek, 2017) and, on the other, in the possibility of engaging them in the realization of their own tourism experiences, which represents an important basis for innovation (García-Rosell et al., 2019).

Thus, the link to the place, allow forming and using essential arguments for the competitiveness and innovation generated by LE, being an essential source of business opportunities (Yachin, 2019), which are materialized in innovative ways of 'selling the place' to tourists (Schilar \& Keskitalo, 2018). Furthermore, the literature recognizes that place familiarity cannot be sufficient to generate innovation because it depends on the ability of the entrepreneur to transform the opportunities and knowledge resulting from the link to the place (Dias et al., 2020b). As such, we hypothesize:

| H1. Place familiarity positively influences innovation

H1i. Relational capital mediates the relationship between place familiarity and Innovation

H2. Place familiarity positively influences relational capital

\subsection{Relational capital and innovation}

Besides the link to the place, we argue that relational capital of the LE also plays an important role on innovation. Relational capital, in this study context, is defined as the close interaction at the personal level between partners (Kale et al., 2000). In the same way, innovation can be defined as the process of introducing new ideas to the firm which result in increased firm performance (Rogers, 2004). The process of innovation in tourism is described as complex (Cooper, 2015)resulting in additional difficulties for small-scale businesses (Dias et al., 2021; Hoarau, 2014). However, LE can boost their small scale in their favor, as it allows greater proximity to the various stakeholders. In the case of customers, it allows them better understand the demands of tourists (Ateljevic \& Doorne, 2000) and to deliver more immersive and tailor-made experiences (Andersson Cederholm \& Hultman, 2010; Richards, 2011; Shaw \& Williams, 2009) developed through co-creation processes (Hall \& Williams, 2019). They also show a greater involvement in community activities (Marchant \& Mottiar, 2011). Furthermore, together with being locally embedded, their small size also allows them to be closer to other local stakeholders (Yachin, 2019), which is essential in the current context of tourism where the traditional value chain gives place to intricate networks of actors (Richards, 2011).

Operating a business in this context requires the ability to articulate with a network of partners who contribute to the total tourism experience, where innovation is increasingly tied to a non-separation between demand and supply 
(Binkhorst \& Den Dekker, 2009). This can be a major setback since most of the rural entrepreneurs are lonely riders (Komppula, 2014). In this context, the ability to innovate is strongly linked to the personal competencies and life and market experience (Ioannides \& Petersen, 2003), especially that of developing his network through relational capital (Bredvold \& Skålén, 2016; Thomas et al., 2011). In this way, LE brings the entrepreneurial spirit to which Morrison refers (2006) and that provides vitality to the experiences of a touristic destination (Kibler et al., 2015). Hall (2004) identified that the existence of a shared environment is essential for the exchange of knowledge and innovation of entrepreneurs. However, having a good relational capital maybe insufficient to generate innovation in these small firms (Cooper, 2015). It will depend on the ability of the entrepreneur to absorb knowledge and opportunities resulting from these links to local partners (Dias et al., 2020b). As such, knowledge absorption can act as a mediator in the relationship between relational capital and innovation. Furthermore, as the place acquires an essential role in LE opportunity recognition and innovation (Arias \& Cruz, 2019; Yachin, 2019), local embeddedness developed through relational capital plays an important (Bosworth \& Farrell, 2011). Accordingly we hypothesize:

| H3. Relational capital positively influences innovation

H3i Knowledge absorption mediates the relationship between relational capital and innovation

H4. Relational capital positively influences knowledge absorption

\subsection{Knowledge absorption and innovation}

Previously we addressed the importance of local knowledge in innovation. However, the literature also states that the transformation of knowledge into innovation depends on the ability to absorb this same knowledge, that is, its integration into the processes, products and services of the firm (Weidenfeld et al., 2010; Yachin, 2019). In the context of this study, knowledge absorption is defined as is the firm's ability to identify, assimilate, and explore the knowledge gained from external sources (Pinheiro et al., 2021). In a competitive environment where local knowledge is continuously evolving (García-Rosell et al., 2019), knowledge absorption supports innovation (Shaw \& Williams, 2009). As such, LE should not only be able to acquire new knowledge (Czernek, 2017) but also to transform it into marketable experiences (Eikhof \& Haunschild, 2006).

The processes through which knowledge is transformed into innovation present some particularities in the case of LE (Kibler et al., 2015). In most cases, the processes are spontaneous and unstructured (Cooper, 2015) such as informal cooperation (Marchant \& Mottiar, 2011) or community centered activities (Dias et al., 2020a). Nevertheless, they do not fail to incorporate a certain degree of market-oriented creativity and innovation [(Ateljevic \& Doorne, 2000; Morrison, 2006). Thus, we propose the following hypothesis:

H5. Knowledge absorption positively influences innovation

\section{Method}

\subsection{Sample and data collection}

The target population for this study are lifestyle entrepreneurs who operates in tourism activities in rural areas of Portugal. The entrepreneurs were selected based on the following inclusion criteria: (i) have a tourism related business (e.g., hotels, hostels, restaurants, tour operators, and visitor attractions) as indicated by Hallak, Assaker, and Lee (2015); (ii) the main activity is performed in a rural area; and (iii) to identify lifestyle entrepreneurs we followed Thomas et al. (2011) definition, meaning that the business are run using financial and non-financial objectives simultaneously or just non-financial objectives.

The data collection took place during the last quarter of 2019, through a face-to-face survey. Since the sampling frame is difficult to define, a non-probabilistic purposive sampling was used to ensure that respondents fit the previously defined criteria. The questionnaire was completed on site by the respondents, obtaining a final sample of 221 valid questionnaires. We also checked if the respondents come from unique businesses to avoid multiple respondents per business.

\subsection{Measures and instrument}

We adopted pre-existing measure to operationalize the variables. As such, to measure knowledge absorption we adopted the six-item scale from Jansen et al. (2005). Place familiarity was adapted from Lalli (1992), consisting of four items. The relational capital measure was adapted from Besser \& Miller (2001), consisting of seven items. Innovation was measured using Kropp, Lindsayand and Shoham's (2006) measures. All the scales were measured using sevenpoint Likert-type scales ranging from 1 = strongly disagree to 7 = strongly agree. The construct indicators are described in appendix A.

These reflective measures were analyzed by a panel of academics specializing in tourism and entrepreneurship. The initial version of the questionnaire was pre-tested on a group of eight lifestyle entrepreneurs to validate the wording and eliminate any ambiguity and errors.

\section{Results and discussion}

To test the conceptual model we used structural equation modelling (SEM), more specifically, a variance-based structural equation modelling technique named partial least squares (PLS). As such, we used SmartPLS 3 software (Ringle et al., 2015). To test the model we followed a twostep procedure. First, we assessed the reliability and validity of the measurement model and, second we analyzed the structural model.

For the first step, we assessed the indicators of reliability, convergent validity, internal consistency reliability, and discriminant validity to evaluate the quality of the measurement model (Hair et al., 2017) (See Table 1). The results revealed that the standardized loadings of all the items of the variables were all significant at $\mathrm{p}<0.001$ and higher than 0.6 (ranging from 0.614 to 0.919 ), providing evidence for reliability of the individual indicator (Hair et al., 2017). 
Table 1. Composite reliability, average variance extracted, correlations, and discriminant validity checks.

\begin{tabular}{lccccccc}
\hline \multicolumn{1}{c}{ Latent Variables } & $\mathbf{\alpha}$ & CR & AVE & $\mathbf{1}$ & $\mathbf{2}$ & $\mathbf{3}$ & $\mathbf{4}$ \\
\hline (1) Innovation & 0,738 & 0,849 & 0,653 & $\mathbf{0 . 8 0 8}$ & 0.644 & 0.584 & 0.821 \\
(2) Knowledge absorption & 0,873 & 0,914 & 0,726 & 0,533 & $\mathbf{0 . 8 5 2}$ & 0.253 & 0.719 \\
(3) Place familiarity & 0,859 & 0,890 & 0,538 & 0,488 & 0,244 & $\mathbf{0 . 7 3 3}$ & 0.293 \\
(4) Relational Capital & 0,828 & 0,887 & 0,666 & 0,715 & 0,614 & 0,280 & $\mathbf{0}$ \\
& & & & & & &
\end{tabular}

Note: $\alpha$-Cronbach Alpha; CR -Composite reliability; AVE -Average variance extracted. Bolded numbers are the square roots of AVE. Below the diagonal elements are the correlations between the constructs. Above the diagonal elements are the HTMT ratios.

Table 2. Structural model assessment.

\begin{tabular}{lcccc}
\hline Path & Path coefficient & Standard errors & t statistics & $p$ values \\
\hline Place familiarity $\rightarrow$ Innovation & 0,303 & 0,053 & 5,697 & 0.000 \\
Place familiarity $\rightarrow$ Relational capital & 0,280 & 0,083 & 3,388 & 0.001 \\
Relational capital $\rightarrow$ Innovation & 0,560 & 0,077 & 7,317 & 0.000 \\
Relational capital $\rightarrow$ Knowledge absorption & 0,614 & 0,064 & 9,536 & 0.000 \\
Knowledge absorption $\rightarrow$ Innovation & 0,115 & 0,070 & 1,651 & 0.099 \\
\hline
\end{tabular}

We used Cronbach alpha and composite reliability (CR) to evaluate the internal consistency of the variables. All surpassed the cut-off of 0.7 (Hair et al., 2017).

The convergent validity was evaluated using three approaches. First, the standardized loadings of all the items were positive and significant on their respective variables. Second, the CR values were superior to 0.70 . Third, the average variance extracted (AVE) for all constructs exceeded the threshold of 0.50 (Bagozzi \& Yi, 1988). To assess the discriminant validity, we used the Fornell and Larcker criterion, meaning that the variables' square root of AVE was superior to its biggest correlation with any construct (Fornell \& Larcker, 1981). For discriminant validity, we also used heterotrait-monotrait ratio (HTMT) criterion (Hair et al., 2017; Henseler et al., 2015), which were below the threshold value of 0.85 (Hair et al., 2017; Henseler et al., 2015). As such, these values provide more evidence of discriminant validity.

To evaluate the accuracy of the structural model we calculated the significance of the structural path coefficients; the dimension of $\mathrm{R}^{2}$ value for each endogenous variable, and the Stone Stone-Geisser's $Q^{2}$ values (Hair et al., 2017). We previously evaluated the collinearity (Hair et al., 2017). As such, we checked the VIF values, which were inferior to the threshold of 5, as recommended by Hair et al. (2017) (ranging from 1.00 to 1.653). These values indicated no collinearity. The $\mathrm{R}^{2}$ (coefficient of the determination) for the three endogenous variables of innovation, knowledge absorption, and relational capital were $61.0 \%, 37.7 \%$, and $10.7 \%$, respectively, and were superior to the threshold value of $10 \%$ (Falk \& Miller, 1992). The $Q^{2}$ values for the three endogenous variables $(0.37,0.27$, and 0.05 respectively) were above zero, providing evidence of the predictive relevance of the model. To test the hypothesis, we used bootstrapping with 5,000 subsamples to evaluate the signif- icance of the parameter estimates (Hair et al., 2017).

The results in Table 2 show that place familiarity has a significantly positive effect on innovation $(\beta=0.303, p<$ 0.001 ) and on relational capital ( $\beta=0.607, p<0.01$ ), and that a relational capital has a significant effect on innovation $(\beta=0.560, \mathrm{p}<0.001)$, and on knowledge absorption ( $\beta=0.614, \mathrm{p}<0.001)$. These results provide support for hypothesis $\mathrm{H} 1$ to $\mathrm{H} 4$, respectively. The relation between knowledge absorption and innovation was not significant ( $\beta=0.115$, n.s.), meaning that $\mathrm{H} 5$ was not supported.

To test the mediation hypotheses (H1i-H3i), we followed the recommendations of Hair et al. (2017; p. 232). Thus, we used a bootstrapping procedure to test the significance of the indirect effects via the mediator (Preacher \& Hayes, 2008). Table 3 presents the results of the mediation effects. The indirect effects of a place familiarity on innovation via the mediator of relational capital $(\beta=0.156 ; p<0.01)$ and relational capital on innovation via the mediator of knowledge absorption $(\beta=0.215 ; p<0.001)$ are significant. These results provide support for $\mathrm{H} 1 \mathrm{i}$ and $\mathrm{H} 3 \mathrm{i}$.

The results reveal that the place familiarity and relational capital influence the innovation generated by LE in rural areas. This means that the degree of integration in the community and the degree of local knowledge provide a basis for both the creation of new products and tourist experiences based on the uniqueness of the space where they develop their activity. These results also expand in two ways the existing knowledge in identifying the determinants of innovation generated by LE in rural areas. First, previous research has focused on the determinants of the context and characteristics of the company (Elena et al., 2015) or the mechanisms of acquisition and assimilation of knowledge (Dias et al., 2020a). This study extends to knowledge by highlighting the combined contribution of the link to the 
Table 3. Bootstrap results for indirect effects.

\begin{tabular}{|c|c|c|c|c|}
\hline Path & $\begin{array}{l}\text { Path } \\
\text { coefficient }\end{array}$ & $\begin{array}{l}\text { Standard } \\
\text { errors }\end{array}$ & $\begin{array}{l}t \\
\text { statistics }\end{array}$ & $\begin{array}{l}p \\
\text { values }\end{array}$ \\
\hline Place familiarity $\rightarrow$ Relational capital $\rightarrow$ Innovation & 0,156 & 0,052 & 3,013 & 0.003 \\
\hline $\begin{array}{l}\text { Relational capital } \rightarrow \text { Knowledge absorption } \rightarrow \\
\text { Innovation }\end{array}$ & 0,172 & 0,057 & 2,996 & 0.003 \\
\hline
\end{tabular}

site and the relationship within the community with the innovation generated. Secondly, this study analyses a specific category of entrepreneurs in the rural context, contributing to the reduced number of studies in this field. Although its importance for innovation in the rural context is recognized (Komppula, 2014), this study helps to better understand which factors may increase this capability.

The results also extend knowledge about the role that relational capital plays both in absorbing knowledge and in transforming the link to the site into innovation. Although place familiarity contributes to innovation, the data suggest that this element is enhanced if there is a high degree of relational capital, which can contribute at several levels. First, the sources of innovation associated with the place, such as traditions, legends and stories, can be enhanced through a close relationship with the local community, facilitating access to this tacit knowledge as proposed by Dias et al. (2020a). Second, because it allows access to other local stakeholders, who can contribute or even be an integral and valuable part of the experiences offered by LE (Hoarau, 2014). Third, they promote better commercial and marketing performance with other stakeholders in the rural value chain, as suggested by Yachin (2019).

The role of knowledge absorption was also identified in its mediating role between relational capital and innovation. This means that it is not enough to access local knowledge and develop the network of contacts in the community and other stakeholders. LE must be able to appropriate that knowledge, integrating it into their products and experiences in a meaningful and market-oriented way. LE should be able to translate the natural and social environment as well as local traditions, stories and legends into innovative narratives and solutions that empower the rural context in which they are inserted. This ability to 'translate' is related to the capacity of these entrepreneurs to be close to clients and to develop personalized experiences (Andersson Cederholm \& Hultman, 2010; Shaw \& Williams, 2009), where the tourist can learn and touch the local culture (Richards, 2011).

Figure 1 depicts the underlying process. The connection to the site and the relational capital provide access to local knowledge. However, it must be integrated into the processes, narratives, products and experiences delivered by LE through knowledge absorption. Under these conditions, knowledge transformation occurs and innovation is generated.

\section{Conclusions}

\subsection{Theoretical contributions}

This study aimed to extend existing knowledge about in-

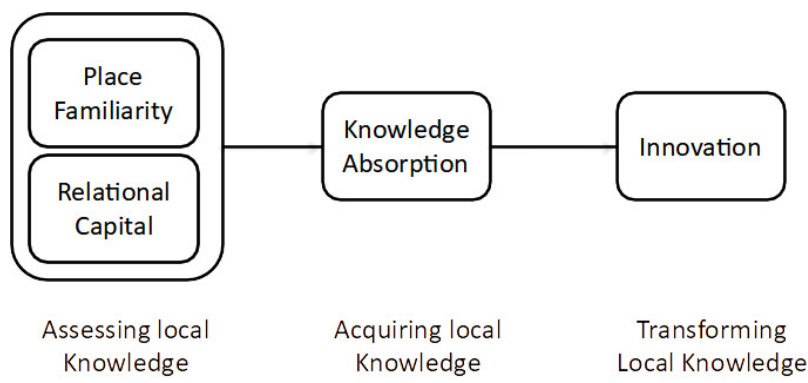

Figure 1. The transformation process of local knowledge into innovation

novation antecedents such as the link to the place and relational capital in the context of rural LE. The results indicate not only that both factors positively influence innovation, but also that they leverage each other, revealing that rooting in the local community together with the ability to establish a network of local contacts represent essential elements for the competitiveness and innovation of these small businesses in rural areas. To our best knowledge, this is the first study to empirically establish this relationship.

Another objective of this study is to identify the role of knowledge absorption in the innovation generated by LE. During this study, some mediating relationships were analyzed, in particular of social capital and knowledge absorption. It was found that both play a role in fostering innovation, revealing that there is interdependence between the variables, suggesting that there is an accumulation of factors that contribute to the innovation of LE in rural areas. Thus, this study contributes to understand the mechanisms associated with innovation which, although they cannot be understood as formal and structured processes, presents a sequence that begins in the access to knowledge through knowledge absorption.

\subsection{Managerial and policy making contributions}

The results of this study point to important insights for destination managers and local and regional policy makers. Considering that these entrepreneurs represent an important contribution to the innovation and vitality of the destinations, it will be important to enhance their innovative capacity. According to the results of the study, familiarity with the place is important, which is valid for locals as well as for entrepreneurs from abroad. The stimulation of deepening knowledge about history, traditions, physical and environmental characteristics, among others, is a way to broaden the range of opportunities to innovate in the experiences, 
paradoxically, based on knowledge that is likely to be ancestral, but which enhances the genuineness of the experiences delivered.

The creation of formal and informal mechanisms that provide more contacts and networking will be another important initiative to develop, such as fairs, contests, events, or social networks are mechanisms that favor the exchange of knowledge and the development of the social capital of entrepreneurs, providing important opportunities to access new knowledge or create collaborative networks to deliver more immersive and creative experiences.

A third important aspect is the development of knowledge absorption skills, which can be achieved through training, documentation, collective or local brands, or other repositories where knowledge can be learned and interpreted.

\subsection{Limitations and future research}

This study presents some limitations and points to avenues for future investigations. First of all, the sample concerns a country. Although Portugal is in the upper quartile of global entrepreneurship, which allows us to analyze the results in the context of other countries, it will always be interesting to understand the cultural differences and the implications they have on the model studied. Secondly, the convenience sample resulted from the fact that not all LE are known in a rural context. The exploration of different segments of entrepreneurs could bring important insights to the results of this study, such as gender, place of birth, age, or employment situation. With a more robust sample, it will be interesting to study the hypothesized relationships variation between different business types. Future research can also explore some moderating effects. For example, the hypothesized relationship between knowledge assimilation and innovation was not statistically supported. However, knowledge assimilation acts as a mediator in the relationship between relational capital and innovation. Although this relationship adheres to the literature, it might act also as a moderator. 


\section{REFERENCES}

Anderson, J. (2012). Relational places: The surfed wave as assemblage and convergence. Environment and Planning D: Society and Space, 30(4), 570-587. http s://doi.org/10.1068/d17910

Andersson Cederholm, E., \& Hultman, J. (2010). The value of intimacy-negotiating commercial relationships in lifestyle entrepreneurship. Scandinavian Journal of Hospitality and Tourism, 10(1), 16-32. https://doi.org/10.1080/15022250903442096

Arias, R. A. C., \& Cruz, A. D. (2019). Rethinking artisan entrepreneurship in a small island. International Journal of Entrepreneurial Behavior \& Research, 25(4), 633-651. https://doi.org/10.1108/ijebr-02-2018-0111

Ateljevic, I., \& Doorne, S. (2000). "Staying within the fence": Lifestyle entrepreneurship in tourism. Journal of Sustainable Tourism, 8(5), 378-392. https://doi.org/ 10.1080/09669580008667374

Bagozzi, R. P., \& Yi, Y. (1988). On the evaluation of structural equation models. Journal of the Academy of Marketing Science, 16(1), 74-94. https://doi.org/10.10 $\underline{07 / \mathrm{bf} 02723327}$

Besser, T. L., \& Miller, N. (2001). Is the good corporation dead? The community social responsibility of small business operators. The Journal of Socio-Economics, 30(3), 221-241. https://doi.org/10.1016/s1053-5357(0 1)00094-4

Binkhorst, E., \& Den Dekker, T. (2009). Agenda for cocreation tourism experience research. Journal of Hospitality Marketing \& Management, 18(2-3), 311-327. https://doi.org/10.1080/19368620802594193

Bosworth, G., \& Farrell, H. (2011). Tourism entrepreneurs in Northumberland. Annals of Tourism Research, 38(4), 1474-1494. https://doi.org/10.1016/ j.annals.2011.03.015

Bredvold, R., \& Skålén, P. (2016). Lifestyle entrepreneurs and their identity construction: A study of the tourism industry. Tourism Management, 56, 96-105. https://doi.org/10.1016/i.tourman.2016.0 $\underline{3.023}$

Carlsen, J., Morrison, A., \& Weber, P. (2008). Lifestyle oriented small tourism firms. Tourism Recreation Research, 33(3), 255-263. https://doi.org/10.1080/025 $\underline{08281.2008 .11081549}$

Cooper, C. (2015). Managing tourism knowledge. Tourism Recreation Research, 40(1), 107-119. https://d oi.org/10.1080/02508281.2015.1006418

Czernek, K. (2017). Tourism features as determinants of knowledge transfer in the process of tourist cooperation. Current Issues in Tourism, 20(2), 204-220. https://doi.org/10.1080/13683500.2014.944 107

Dias, Á., González - Rodríguez, M. R., \& Patuleia, M. (2021). Retaining tourism lifestyle entrepreneurs for destination competitiveness. International Journal of Tourism Research, 23(4), 701-712. https://doi.org/10.1 002/jtr.2436
Dias, Á., Silva, G. M., Patuleia, M., \& GonzálezRodríguez, M. R. (2020a). Developing sustainable business models: Local knowledge acquisition and tourism lifestyle entrepreneurship. Journal of Sustainable Tourism, 1-20. https://doi.org/10.1080/09 $\underline{669582.2020 .1835931}$

Dias, Á., Silva, G. M., Patuleia, M., \& GonzálezRodríguez, M. R. (2020b). Transforming local knowledge into lifestyle entrepreneur's innovativeness: Exploring the linear and quadratic relationships. Current Issues in Tourism, 1-17. http s://doi.org/10.1080/13683500.2020.1865288

Eikhof, D. R., \& Haunschild, A. (2006). Lifestyle meets market: Bohemian entrepreneurs in creative industries. Creativity and Innovation Management, 15(3), 234-241. https://doi.org/10.1111/j.1467-8691.2 006.00392.x

Elena, H., Sorina, M., \& Rus, D. (2015). A predictive model of innovation in rural entrepreneurship. Procedia Technology, 19, 471-478. https://doi.org/10.1 016/i.protcy.2015.02.067

Falk, R. F., \& Miller, N. B. (1992). A primer for soft modelling. University of Akron Press.

Fornell, C., \& Larcker, D. F. (1981). Evaluating structural equation models with unobservable variables and measurement error. Journal of Marketing Research, 18(1), 29-50. https://doi.org/10.2307/3151312

Fu, H., Okumus, F., Wu, K., \& Köseoglu, M. A. (2019). The entrepreneurship research in hospitality and tourism. International Journal of Hospitality Management, 78, 1-12. https://doi.org/10.1016/j.ijh m.2018.10.005

García-Rosell, J.-C., Haanpää, M., \& Janhunen, J. (2019). 'Dig where you stand': values-based co-creation through improvisation. Tourism Recreation Research, 44(3), 348-358. https://doi.org/10.1080/02508281.201 $\underline{9.1591780}$

Getz, D., \& Carlsen, J. (2000). Characteristics and goals of family and owner-operated businesses in the rural tourism and hospitality sectors. Tourism Management, 21(6), 547-560. https://doi.org/10.1016/s0261-5177(0 0)00004-2

Hair, J. F., Jr., Hult, G. M., Ringle, C., \& Sarstedt, M. (2017). A primer on partial least squares structural equation modeling (PLS-SEM). Sage Publications.

Hall, C. M. (2019). Constructing sustainable tourism development: The 2030 agenda and the managerial ecology of sustainable tourism. Journal of Sustainable Tourism, 27(7), 1044-1060. https://doi.org/10.1080/09 $\underline{669582.2018 .1560456}$

Hall, C. M., \& Williams, A. M. (Eds.). (2019). Tourism and innovation. Routledge. https://doi.org/10.4324/97 81315162836

Henseler, J., Ringle, C. M., \& Sarstedt, M. (2015). A new criterion for assessing discriminant validity in variance-based structural equation modeling. Journal of the Academy of Marketing Science, 43(1), 115-135. $\underline{\mathrm{h}}$ ttps://doi.org/10.1007/s11747-014-0403-8 
Hjalager, A.-M., Kwiatkowski, G., \& Østervig Larsen, M. (2018). Innovation gaps in Scandinavian rural tourism. Scandinavian Journal of Hospitality and Tourism, 18(1), 1-17. https://doi.org/10.1080/1502225 $\underline{0.2017 .1287002}$

Hoarau, H. (2014). Knowledge acquisition and assimilation in tourism-innovation processes. Scandinavian Journal of Hospitality and Tourism, 14(2), 135-151. https://doi.org/10.1080/15022250.2014.887 $\underline{609}$

Ioannides, D., \& Petersen, T. (2003). Tourism 'nonentrepreneurship' in peripheral destinations: a case study of small and medium tourism enterprises on Bornholm, Denmark. Tourism Geographies, 5(4), 408-435. https://doi.org/10.1080/1461668032000129 146

Jack, S. L., \& Anderson, A. R. (2002). The effects of embeddedness on the entrepreneurial process. Journal of Business Venturing, 17(5), 467-487. https://d oi.org/10.1016/s0883-9026(01)00076-3

Jansen, J. J. P., Van Den Bosch, F. A. J., \& Volberda, H. W. (2005). Managing potential and realized absorptive capacity: How do organizational antecedents matter? Academy of Management Journal, 48(6), 999-1015. htt ps://doi.org/10.5465/amj.2005.19573106

Kale, P., Singh, H., \& Perlmutter, H. (2000). Learning and protection of proprietary assets in strategic alliances: Building relational capital. Strategic Management Journal, 21(3), 217-237. https://doi.org/1 0.1002/(sici)1097-0266(200003)21:3

Kibler, E., Fink, M., Lang, R., \& Muñoz, P. (2015). Place attachment and social legitimacy: Revisiting the sustainable entrepreneurship journey. Journal of Business Venturing Insights, 3, 24-29. https://doi.org/1 $\underline{0.1016 / j . j b v i .2015 .04 .001}$

Komppula, R. (2014). The role of individual entrepreneurs in the development of competitiveness for a rural tourism destination - A case study. Tourism Management, 40, 361-371. https://doi.org/1 0.1016/j.tourman.2013.07.007

Korsgaard, S., Müller, S., \& Tanvig, H. W. (2015). Rural entrepreneurship or entrepreneurship in the rural between place and space. International Journal of Entrepreneurial Behavior \& Research, 21(1), 5-26. http s://doi.org/10.1108/ijebr-11-2013-0205

Kropp, F., Lindsay, N. J., \& Shoham, A. (2006). Entrepreneurial, market, and learning orientations and international entrepreneurial business venture performance in South African firms. International Marketing Review, 23(5), 504-523. https://doi.org/10.1 108/02651330610703427

Lalli, M. (1992). Urban-related identity: Theory, measurement, and empirical findings. Journal of Environmental Psychology, 12(4), 285-303. https://do i.org/10.1016/s0272-4944(05)80078-7

Marchant, B., \& Mottiar, Z. (2011). Understanding lifestyle entrepreneurs and digging beneath the issue of profits: Profiling surf tourism lifestyle entrepreneurs in Ireland. Tourism Planning \& Development, 8(2), 171-183. https://doi.org/10.1080/2 $\underline{1568316.2011 .573917}$
Morrison, A. (2006). A contextualisation of entrepreneurship. International Journal of Entrepreneurial Behavior \& Research, 12(4), 192-209. https://doi.org/10.1108/13552550610679159

Pinheiro, J., Lages, L. F., Silva, G. M., Dias, A. L., \& Preto, M. T. (2021). Effects of absorptive capacity and innovation spillover on manufacturing flexibility. International Journal of Productivity and Performance Management, Published ahead of print, 1-22. https://d oi.org/10.1108/ijppm-04-2020-0156

Preacher, K. J., \& Hayes, A. F. (2008). Asymptotic and resampling strategies for assessing and comparing indirect effects in multiple mediator models. Behavior Research Methods, 40(3), 879-891. https://doi.org/1 $\underline{0.3758 / \mathrm{brm} .40 .3 .879}$

Richards, G. (2011). Creativity and tourism: The state of the art. Annals of Tourism Research, 38(4), 1225-1253. https://doi.org/10.1016/j.annals.2011.07.008

Ringle, C. M., Wende, S., \& Will, A. (2015). SmartPLS3.0. https://www.smartpls.de

Rogers, M. (2004). Networks, firm size and innovation. Small Business Economics, 22(2), 141-153. https://do i.org/10.1023/b:sbej.0000014451.99047.69

Schilar, H., \& Keskitalo, E. H. (2018). Tourism activity as an expression of place attachment-place perceptions among tourism actors in the Jukkasjärvi area of northern Sweden. Scandinavian Journal of Hospitality and Tourism, 18(sup1), 42-59. https://doi.org/10.108 $\underline{0 / 15022250.2017 .1389123}$

Shaw, G., \& Williams, A. (2009). Knowledge transfer and management in tourism organisations: An emerging research agenda. Tourism Management, 30(3), 325-335. https://doi.org/10.1016/j.tourman.2008.02.0 $\underline{23}$

Stamboulis, Y., \& Skayannis, P. (2003). Innovation strategies and technology for experience-based tourism. Tourism Management, 24(1), 35-43. https://d oi.org/10.1016/s0261-5177(02)00047-X

Tan, W.-K., \& Chang, Y.-G. (2016). Place familiarity and attachment: moderators of the relationship between readers' credibility assessment of a travel blog and review acceptance. Journal of Travel \& Tourism Marketing, 33(4), 453-470. https://doi.org/10.1080/10 548408.2015.1064059

Thomas, R., Shaw, G., \& Page, S. J. (2011). Understanding small firms in tourism: A perspective on research trends and challenges. Tourism Management, 32(5), 963-976. https://doi.org/10.1016/ j.tourman.2011.02.003

Valtonen, A. (2009). Small tourism firms as agents of critical knowledge. Tourist Studies, 9(2), 127-143. http s://doi.org/10.1177/1468797609360600

Wang, C., Li, G., \& Xu, H. (2019). Impact of lifestyleoriented motivation on small tourism enterprises' social responsibility and performance. Journal of Travel Research, 58(7), 1146-1160. https://doi.org/1 $\underline{0.1177 / 0047287518800389}$

Weidenfeld, A., Williams, A. M., \& Butler, R. W. (2010). Knowledge transfer and innovation among attractions. Annals of Tourism Research, 37(3), 604-626. https://doi.org/10.1016/j.annals.2009.12.00 1 
Xiong, Y., Zhang, Y., \& Lee, T. J. (2020). The rural creative class: An analysis of in - migration tourism entrepreneurship. International Journal of Tourism Research, 22(1), 42-53. https://doi.org/10.1002/jtr.231 $\underline{7}$

Yachin, J. M. (2019). The entrepreneur-opportunity nexus: Discovering the forces that promote product innovations in rural micro-tourism firms. Scandinavian Journal of Hospitality and Tourism, 19(1), 47-65. https://doi.org/10.1080/15022250.2017.138393 $\underline{6}$
Zhang, C., Xiao, H., Gursoy, D., \& Rao, Y. (2015). Tacit knowledge spillover and sustainability in destination development. Journal of Sustainable Tourism, 23(7), 1029-1048. https://doi.org/10.1080/09669582.2015.1 $\underline{032299}$ 


\section{Appendix}

\section{Construct indicators}

\section{Constructs and items}

Innovation (1 = No confidence, 5 = Totally secure)

Indicate your degree of confidence in yourself..

Successfully identify new opportunities

Create new products

Think creatively

Market an idea or a new solution

Knowledge absorption ( 1 = Strongly disagree; $7=$ Totally agree)

Consider the following statements and indicate your agreement..

We participate in events or training on local habits or traditions

We obtain knowledge through informal means (lunches ...)

We learn new ideas and services with clients.

We consult local people about local habits and traditions.

We quickly turn opportunities into new services.

We quickly see the changes that occur in the market.

Place familiarity (1= Strongly disagree; $7=$ Totally agree)

Consider the following statements and indicate your agreement...

I feel that I belong to this place

This place is very familiar

This place is very important for my daily life

I live this place intensely

Relational Capital (1=Less important; 7=Very important)

Please indicate the importance of the following activities...

I seek to strengthen and improve the local community

I seek to improve my image with the local community

I am addressing clients that are not served by other local companies

I cooperate with other companies / local entrepreneurs

I'm involved in local festivals and other events

I support local projects 